\title{
Diversity enhances carbon storage in tropical forests
}

Poorter, L.; van der Sande, M.T.; Thompson, J.; Arets, E.J.; Alarcón, A.; Álvarez-Sánchez, J.; Ascarrunz, N.; Balvanera, P.; Barajas-Guzmán, G.; Boit, A.; Bongers, F.; Carvalho, F.A.; Casanoves, F.; Cornejo-Tenorio, G.; Costa, F.R.; de Castilho, C.V.; Duivenvoorden, J.F.; Dutrieux, L.P.; Enquist, B.J.; Fernández-Méndez, F.; Finegan, B.; Gormley, Lorraine; Healey, J.R.; Hoosbeek, M.R.; Ibarra-Manríquez, G.; Junqueira, A.B.; Levis, C.; Licona, J.C.; Lisboa, L.S.; Magnusson, W.E.; Martínez-Ramos, M.; Martínez-Yrizar, A.; Martorano, L.G.; Maskell, L.C.; Mazzei, L.; Meave, J.A.; Mora, F.; Muñoz, R.; Nytch, C.; Pansonato, M.P.; Parr, T.W.; Paz, H.; Pérez-García, E.A.; Rentería, L.Y.; Rodríguez-Velazquez, J.; Rozendaal, D.M.; Ruschel, A.R.; Sakschewski, B.; Salgado-Negret, B.; Schietti, J.; Simões, M.; Sinclair, F.L.; Souza, P.F.; Souza, F.C.; Stropp, J.; ter Steege, H.; Swenson, N.G.; Thonicke, K.; Toledo, M.; Uriarte, M.; van der Hout, P.; Walker, P.; Zamora, N.; and Peña-Cllaros, M.

\section{Global Ecology and Biogeography}

DOI:

10.1111/geb.12364

Published: 08/09/2015

Peer reviewed version

Cyswllt i'r cyhoeddiad / Link to publication

Dyfyniad o'r fersiwn a gyhoeddwyd / Citation for published version (APA):

Poorter, L., van der Sande, M. T., Thompson, J., Arets, E. J., Alarcón, A., Álvarez-Sánchez, J., Ascarrunz, N., Balvanera, P., Barajas-Guzmán, G., Boit, A., Bongers, F., Carvalho, F. A., Casanoves, F., Cornejo-Tenorio, G., Costa, F. R., de Castilho, C. V., Duivenvoorden, J. F. Dutrieux, L. P., Enquist, B. J., ... and Peña-Claros, M. (2015). Diversity enhances carbon storage in tropical forests. Global Ecology and Biogeography, 24(11), 1314-1328.

https://doi.org/10.1111/geb.12364

Hawliau Cyffredinol / General rights

Copyright and moral rights for the publications made accessible in the public portal are retained by the authors and/or other copyright owners and it is a condition of accessing publications that users recognise and abide by the legal requirements associated with these rights.

study or research.

- Users may download and print one copy of any publication from the public portal for the purpose of private

- You may not further distribute the material or use it for any profit-making activity or commercial gain

- You may freely distribute the URL identifying the publication in the public portal ?

Take down policy

This is the peer reviewed version of the article, which has been published in final form at

http://dx.doi.org/10.1111/geb.12364. This article may be used for non-commercial purposes in accordance with Wiley

Terms and Conditions for Self-Archiving. () 2015 John Wiley \& Sons Ltd

Take down policy

If you believe that this document breaches copyright please contact us providing details, and we will remove access to the work immediately and investigate your claim. 
3 Authors: L. Poorter ${ }^{1}$; M. T. van der $\operatorname{Sande}^{1,2}$; J. Thompson ${ }^{3,4}$; E. J. M. M. Arets ${ }^{2}$; A. Alarcón ${ }^{5}$; J. Álvarez-

4 Sánchez ${ }^{6}$; N. Ascarrunz $;$; P. Balvanera ${ }^{7}$; G. Barajas-Guzmán ${ }^{6}$; A. Boit ${ }^{8}$; F. Bongers ${ }^{1}$; F. A. Carvalho ${ }^{9}$; F.

5 Casanoves $^{10}$; G. Cornejo-Tenorio ${ }^{7}$; F. R. C. Costa ; C. V. de Castilho ${ }^{11}$; J. F. Duivenvoorden ${ }^{12}$; L. P.

6 Dutrieux ${ }^{13}$; B. J. Enquist ${ }^{14}$; F. Fernández-Méndez ${ }^{15}$; B. Finegan ${ }^{16}$; L. H. L. Gormley ${ }^{17}$; J. R. Healey ${ }^{17}$; M.

7 R. Hoosbeek ${ }^{18}$; G. Ibarra-Manríquez ${ }^{7}$; A. B. Junqueira ${ }^{9,19,20}$; C. Levis ${ }^{1,9}$; J. C. Licona ${ }^{5}$; L. S. Lisboa ${ }^{21}$; W.

8 E. Magnusson ${ }^{9}$; M. Martínez-Ramos ; A. Martínez-Yrizar ${ }^{22}$; L. G. Martorano ${ }^{23}$; L. C. Maskell ${ }^{24}$; L.

9 Mazzei ${ }^{23}$; J. A. Meave ${ }^{6}$ F. Mora ${ }^{7}$; R. Muñoz ${ }^{6}$; C. Nytch ${ }^{4}$; M. P. Pansonato ; T. W. Parr ${ }^{24}$; H. Paz $;$; M.

10 Simoes Penello ${ }^{25}$; E. A. Pérez-García ${ }^{6}$; L. Y. Rentería ${ }^{7}$;. Rodríguez-Velazquez ${ }^{7}$; D. M. A. Rozendaal ${ }^{1,26}$;

11 A. R. Ruschel ${ }^{23}$; B. Sakschewski ${ }^{8}$; B. Salgado $\operatorname{Negret}^{27}$; J. Schietti ${ }^{9}$; F. L. Sinclair ${ }^{17,28}$; P. F. Souza ${ }^{9}$ F. C.

12 Souza $^{9}$; J. Stropp ${ }^{29}$; H. ter Steege ${ }^{30}$, 31 ; N. G. Swenson ${ }^{32}$; K. Thonicke ${ }^{8}$; M. Toledo ${ }^{5}$; M. Uriarte ${ }^{33}$; P. van

13 der Hout ${ }^{34}$; P. Walker ${ }^{35}$; N. Zamora ${ }^{36}$; M. Peña-Claros ${ }^{1}$

${ }^{1}$ Forest Ecology and Forest Management Group, Wageningen University, P.O. Box 47, 6700 AA Wageningen, The Netherlands

2 Alterra Wageningen UR, Wageningen, The Netherlands

${ }^{3}$ Centre for Ecology \& Hydrology, Penicuik, UK

${ }^{4}$ Department of Environmental Science, University of Puerto Rico, Río Piedras, Puerto Rico

${ }^{5}$ Instituto Boliviano de Investigación Forestal (IBIF), FCA-UAGRM, Santa Cruz de la Sierra, Bolivia

${ }^{6}$ Facultad de Ciencias, Universidad Nacional Autónoma de México, México D.F., México

${ }^{7}$ Centro de Investigaciones en Ecosistemas, Universidad Nacional Autónoma de México, Morelia, México

${ }^{8}$ Potsdam Institute for Climate Impact Research e.V. (PIK), Potsdam, Germany and Berlin-Brandenburg Institute of Advanced Biodiversity Research (BBIB), 14195 Berlin, Germany

${ }^{9}$ Instituto Nacional de Pesquisas da Amazônia (INPA), Manaus, Brazil

${ }^{10}$ Biostatistics Unit, CATIE, Turrialba, Costa Rica

${ }^{11}$ Embrapa Roraima, Boa Vista, Brazil

${ }^{12}$ IBED, University of Amsterdam, Amsterdam, The Netherlands

${ }^{13}$ Lab of GIS and Remote-Sensing, Wageningen University, Wageningen, The Netherlands

${ }^{14}$ Department of Ecology \& Evolutionary Biology, The University of Arizona, Tucson, USA

${ }^{15}$ Grupo de Investigación en Biodiversidad y Dinámica de Ecosistemas Tropicales, Universidad del Tolima, Ibagué, Colombia

${ }^{16}$ Production and Conservation in Forests Programme, CATIE, Turrialba, Costa Rica

${ }^{17}$ School of Environment, Natural Resources and Geography, Bangor University, Bangor, UK

${ }^{18}$ Department of Soil Quality, Wageningen University, Wageningen, The Netherlands

${ }^{19}$ Centre for Crop Systems Analysis Wageningen University, Wageningen, The Netherlands

${ }^{20}$ Knowledge, Technology and Innovation Group, Wageningen University, Wageningen, The Netherlands

${ }^{21}$ ESALQ, USP, Piracicaba, Brazil

22 Instituto de Ecología, UNAM, Hermosillo, Mexico

${ }^{23}$ Embrapa Amazônia Oriental, Belém, Brazil

${ }^{24}$ Centre for Ecology \& Hydrology (CEH), Lancaster, UK

${ }^{25}$ Embrapa Solos, Rio de Janeiro, Brazil

${ }^{26}$ Department of Ecology and Evolutionary Biology, University of Connecticut, Storrs, USA

${ }^{27}$ Instituto de Investigación de Recursos Biológicos Alexander von Humboldt, Bogotá, Colombia

${ }^{28}$ World Agroforestry Centre (ICRAF), Nairobi, Kenya

${ }^{29}$ European Commission, Directorate General - Joint Research Centre, Institute for Environment and Sustainability, Ispra, Italy 
14 Running title: Carbon storage in tropical forests

15

16 Corresponding author:

17

18 Lourens Poorter

19 Forest Ecology and Forest Management Group, Wageningen University

20 P.O. Box 47, 6700 AA Wageningen, The Netherlands

21 E-mail: lourens.poorter@wur.nl

22

23 Number of words in abstract: 298

24 Number of words in main body: 8679

25 Number of references: 50

26

${ }^{30}$ Naturalis Biodiversity Center, Leiden, Netherlands.

${ }^{31}$ Ecology and Biodiversity Group, Utrecht University, Utrecht, The Netherlands

${ }^{32}$ Department of Plant Biology, Michigan State University, Michigan, USA

${ }^{33}$ Department of Ecology, Evolution \& Environmental Biology, Columbia University, New York, USA

${ }^{34}$ Van der Hout Forestry Consulting, Rotterdam, The Netherlands

${ }^{35}$ Wildtracks, P.O.Box 278, Belize City, Belize

${ }^{36}$ Instituto Nacional de Biodiversidad (INBio), Santo Domingo, Costa Rica 
27 Key-words: biodiversity, biomass, scale, ecosystem functioning, Neotropics, rainfall, REDD+, soil,

28 tropical forest

\section{Abstract}

32 Aim Tropical forests store $25 \%$ of the global carbon and harbor $96 \%$ of the world's tree species, but it is

33 not clear whether this high biodiversity matters for carbon storage. Few studies have teased apart the

34 relative importance of forest attributes and environmental drivers for ecosystem functioning, and no such

35 study exists for the tropics.

36 Location Neotropics

37 Methods We relate aboveground biomass (AGB) to forest attributes (diversity and structure) and 38 environmental drivers (annual rainfall and soil fertility) using data from 144,000 trees, 2,050 forest plots

39 and 59 forest sites. The sites span the complete latitudinal and climatic gradients in the lowland

40 Neotropics, with rainfall ranging from 750 to $4350 \mathrm{~mm} / \mathrm{y}$. Relationships were analyzed within forest sites

41 at 0.1 ha and 1 ha scale, and across forest sites along large-scale environmental gradients. We used a

42 structural equation model to test the hypothesis that species richness, forest structural attributes, and

43 environmental drivers have independent, positive effects on AGB.

44 Results Across sites, AGB was most strongly driven by rainfall, followed by average tree stem diameter

45 and rarefied species richness, which all had positive effects on AGB. Our indicator of soil fertility (cation

46 exchange capacity) had a negligible effect on AGB, perhaps because we used a global soil database.

47 Taxonomic forest attributes (i.e., species richness, rarefied richness and Shannon diversity) had the

48 strongest relationships with AGB at small spatial scales, where an additional species can still make a

49 difference in terms of niche complementarity, whereas structural forest attributes (i.e., tree density and

50 tree size) had strong relationships with AGB at all spatial scales. 
51 Main conclusions Biodiversity has an independent, positive effect on AGB and ecosystem functioning,

52 not only in relatively simple temperate systems, but also in structurally complex hyperdiverse tropical

53 forests. Biodiversity conservation should therefore be a key component of REDD+ strategies.

54

55

56

57

58 Tropical forests are hotspots for carbon and biodiversity; they only cover 7-10 \% of the Earth's land

59 surface, but store $25 \%$ of the terrestrial above- and below-ground carbon (Bonan, 2008), are responsible

60 for $34 \%$ of terrestrial primary productivity (Beer et al., 2010), and harbor $96 \%$ of the estimated 45,000

61 tree species in the world (Fine et al., 2008). From a practical point of view, this provides a win-win

62 situation for the UN- Reduced Emissions from Deforestation and Degradation (REDD+) initiative, which

63 aims to conserve carbon storage of tropical forest while safeguarding biodiversity. Importantly,

64 biodiversity conservation can be much more than a side benefit alone, if a higher biodiversity enhances

65 carbon sequestration and storage (Díaz et al., 2009). Forest functioning may not only be determined by

taxonomic attributes (i.e., measures of species identity) of the vegetation, but also by structural attributes,

67 and by the direct and indirect effects of environmental drivers (see the conceptual model in Fig. 1a).

68 Surprisingly few studies have teased apart the relative importance of these environmental drivers and

69 forest attributes for ecosystem properties and processes (but see Paquette \& Messier, 2011; Vila et al.,

70 2013).

71 Over the past two decades there has been a strong emphasis on the role of biodiversity in

72 ecosystem properties, processes, and services (Naeem et al., 2009 and references therein). Species

73 richness is thought to enhance productivity through: (1) niche complementarity, where species have

74 different niches, and are therefore able to access more of the available resources or facilitating each other,

75 thus enhancing overall productivity (Tilman et al., 2001); (2) the selection effect, as by chance a very

76 productive species is included in the community (Loreau \& Hector, 2001); (3) the insurance effect, as one 
77 species contributes more to ecosystem productivity in one year, and another species in another year (Yachi

78 \& Loreau, 1999; Isbell et al., 2011). These hypotheses about the relationship between species richness and

79 productivity could also apply to standing biomass, as higher productivity may lead to faster biomass

80 accumulation, and productivity and biomass are therefore positively correlated in forests (Chisholm et al.,

$812013)$.

82 Not only taxonomic attributes (i.e., species identity), but also structural attributes, such as stem

83 diameter, tree density and leaf area index, determine biomass, resource capture and productivity.

84 Vegetation structure contributes directly to biomass, but variation in structure such as leaf layering may

85 also enhance light capture and carbon gain. Structural attributes may vary more strongly within

86 communities (due to disturbances) and across communities (due to environmental gradients) than

87 taxonomic attributes, and may have a larger direct impact on biomass and ecosystem processes. A recent

88 study found, for example, that vegetation quantity (biomass) rather than vegetation quality (i.e., species

89 functional traits and variation therein) was the main driver of productivity in tropical secondary forests

90 (Lohbeck et al., 2015). The question is therefore whether taxonomic attributes may explain any additional

91 variation in above-ground biomass (AGB), once the role of structural attributes has explicitly been taken

92 into account (Fig. 1a).

93 A recent meta-analysis showed that in experimental studies species richness increased primary

94 productivity and standing biomass and that biodiversity loss has, therefore, a negative effect on ecosystem

95 functioning (Cardinale et al., 2011). However, most studies included in the meta-analysis were carried out

96 at small spatial scales, and involved grasslands and aquatic systems, and most experiments used a low

97 number of species (less than 10, Cardinale et al., 2011), and thus the effect of high species richness can

98 not be assessed. It is not clear therefore whether the relationship between biodiversity and biomass will

99 also hold for (1) larger spatial scales -where there may be a saturating effect as the number of species rises

100 without a further increase in carbon storage, (2) areas under different environmental control, and (3)

101 hyper-diverse communities in the tropics where many species might be functionally redundant. 
The relationships between species richness, AGB and productivity may vary with spatial scale.

103 Experimental grassland studies and many forest surveys have typically used small plots, and found that 104 the positive effect of species richness on biomass or biomass productivity saturates with only 3-8 species 105 (Tilman et al., 2001; Zhang et al., 2012; Gamfeldt et al., 2013; Vila et al., 2013). Chisholm et al. (2013) 106 found for temperate and tropical forests that species richness and biomass were positively related within 107 forest sites at small spatial scales $(20 \times 20 \mathrm{~m})$, probably because in a small area with relatively few species any additional species still matters for productivity and AGB. At larger spatial scales $(100 \times 100 \mathrm{~m})$ there was no consistent relationship between species richness and biomass, probably as a result of such saturation effect .

The relationship between species richness and productivity may also vary with systems under different environmental conditions. In a study using small survey plots in Canada, Paquette \& Messier (2011) found that in boreal forests facing harsh environmental conditions, functional tree diversity affects productivity strongly and positively, whereas in benign and productive temperate forests diversity has a weaker effect on productivity. Paquette \& Messier hypothesized that in stressful (e.g., cold or dry) environments diversity contributes to facilitation processes and, hence, to productivity, whereas in benign environments diversity results in more competition. It cannot be ruled out, however, that the stronger diversity effect in boreal forests is simply a result of the lower species richness there.

Both taxonomic and structural attributes and ecosystem properties and processes may vary along environmental gradients (Fig. 1a). Species richness of tropical lowland forests tends to increase with 121 rainfall and reduced seasonality (ter Steege et al., 2003). The density of large trees, forest AGB and net 122 primary productivity all increase with resource availability (annual rainfall and soil fertility), and decrease 123 with temperature (Malhi et al., 2004; Baraloto et al., 2011; Quesada et al., 2012; Slik et al., 2013). Hence, environmental drivers are likely to affect AGB either directly, or indirectly via their effect on taxonomic and structural forest attributes (Fig. 1a).

Here we relate aboveground biomass (AGB) to taxonomic and structural forest attributes, as well as to rainfall and soil fertility. We use data from 144,000 trees that were sampled in 2,050 forest plots 
established in 59 forest sites. This dataset spans the complete latitudinal and climatic gradient in the lowland Neotropics (ranging from 750 to $4350 \mathrm{~mm}$ rainfall per year) and covers all major forest types

130 (from dry deciduous- to wet forests, Appendix S1 in Supporting Information). Relationships were

131 analyzed at a local scale under relatively homogeneous environmental conditions within forest sites $(0.1$

132 and 1 ha plots) and at a regional scale along large-scale environmental and biogeographical gradients

133 across forest sites.

134 We address two major questions. First, what are the effects of taxonomic and structural attributes

135 on AGB and what is their relative importance? We hypothesize that species diversity has a positive effect

136 on biomass (through niche complementarity, the selection effect, or the insurance effect) and that this

137 effect can be observed at small ( 0.1 ha) spatial scales (where richness is low, so an additional species still

138 makes a difference) but not at larger (1 ha) spatial scales (because of species redundancy). We predict that

139 as stem density and average stem diameter increases there will be greater AGB, and that they have

140 stronger effects on AGB than taxonomic forest attributes. Second, what are the direct effects of

141 environmental drivers on AGB, and on the taxonomic and structural attributes of the forest? We

142 hypothesize that with an increase in resource availability (water and nutrients) there will be an increase in

143 AGB, forest structure (i.e., tree size) and taxonomic diversity, and that annual rainfall will have a stronger

144 effect than soil fertility given the large climatic gradient considered.

146 Methods

148 Study sites - We compiled information on species diversity, structure and biomass from 2941 ha plots and $149 \quad 1,9750.1$ ha plots established in 59 mature forest sites. that covered nearly the full latitudinal range of 150 Neotropical forests from Mexico to Bolivia (Fig. 2, Appendix S1). Rainfall ranged from 750 to 4350 $151 \mathrm{~mm} / \mathrm{yr}$, and soil Cation Exchange Capacity (CEC) ranged from 1 to $83 \mathrm{cmol} / \mathrm{kg}$. For all analyses we only 152 focus on trees because there was no consistent inventory data for lianas and palms, and in most forests 

S2.

Biomass calculations - We took advantage of available plot data in mature, fully developed "old-growth"

157 forests, without visible effects of past human disturbance. The size, shape, spatial distribution and

158 contiguousness of plots varied across sites (Appendix S1). For this study, we calculated forest attributes at 159 two spatial scales (0.1 ha and 1 ha).

In many plots only trees $\geq 10 \mathrm{~cm}$ stem diameter at breast height (dbh: tree diameter at $1.3 \mathrm{~m}$ from the ground) were measured, but in other plots data for trees $\geq 5 \mathrm{~cm}$ dbh. were also included as these small 162 stems can contribute a significant part of AGB in drier forests. AGB was calculated for plots of 0.1 ha and 1631 ha, as the relationship between AGB and diversity is scale-dependent (Chisholm et al., 2013). For each 164 plot, above-ground biomass was calculated for each tree using six different allometric equations. The 165 allometric equations were based on stem diameter only (Pearson, Brown et al., 2005, henceforth referred 166 to as the "Brown" equations), or a combination of stem diameter and wood density (Chave et al., 2005, 167 henceforth referred to as the "Chave" equations). Brown and Chave both present three different equations 168 for different forest types; dry forest, moist forest and wet forest. For use in the Chave calculations wood 169 density $\left(\mathrm{WD}, \mathrm{g} \mathrm{cm}^{-3}\right.$ ) data came from the local sites, or from the Neotropical data of a global WD database 170 (Zanne et al., 2009, http://datadryad.org/handle/10255/dryad.235). Biomass was then summed across all 171 trees to obtain above-ground plot biomass (AGB, in $\mathrm{Mg} / \mathrm{ha}$ ). We first checked to what extent AGB varied 172 with the type of biomass allometric equation used, and with both diameter cutoff limits (Appendix S3).

173 The Chave and Brown estimates of plot AGB for trees $\geq 10 \mathrm{~cm}$ dbh were tightly related $\left(\mathrm{r}^{2}=0.81\right)$.

174 Estimated plot AGB using the Chave equations was on average 1.15 times the estimated AGB using the 175 Brown equations (paired t-test, $\mathrm{t}=16.1, \mathrm{P}<0.001, \mathrm{~N}=480$ ). Using the Chave equations, the estimated plot 176 AGB for trees $\geq 5 \mathrm{~cm}$ dbh was on average 1.04 times the AGB of trees $\geq 10 \mathrm{~cm}$ dbh and this ratio was 177 especially large for dry forests (on average 1.178) but close to 1 for moist forests (1.033) and wet forests 178 (1.020, Appendix S3). In dry forests, small trees $(5-10 \mathrm{~cm} \mathrm{dbh})$ contribute, therefore, a relatively large 
179 proportion to AGB, although their absolute contribution is small. For further analysis we then used the

180 Chave equations that corresponded to the forest type (dry, moist or wet) that the plot belonged to, and we

181 used trees $\geq 10 \mathrm{~cm} \mathrm{dbh}$, as these data were available for all plots. We used the Chave equations because

182 they include wood density, which is an important source of large-scale variation in AGB (Mitchard et al., 183 2014).

Structural attributes - AGB variation across forest plots is, amongst others, a function of the tree density, mean stem diameter, and wood density of trees. It is therefore not the question whether these variables are related to AGB, but what is their relative strength in determining AGB plot biomass. For each plot, five structural attributes were calculated for which data were available and that are relevant for the biomass model used: overall tree density, density of large trees ( $\geq 60 \mathrm{~cm} \mathrm{dbh})$, mean tree diameter, and stand basal area. Note that individual tree biomass is calculated based on tree diameter, and hence, tree biomass scales closely with the basal area of the individual tree. This is something different from stand basal area. A high stand basal area can be caused by many small trees (that each contain little biomass), or a few trees with large basal area (that each contain a disproportionally large biomass).

Taxonomic attributes- For each plot, three taxonomic attributes were calculated: species richness per area, rarefied species richness per 50 individuals, and Shannon diversity. Rarefied species richness is the number of species observed when a certain number of trees is randomly drawn from a plot. Such rarefaction removes the confounding effect of tree density on species richness. For rarefied richness we used 50 individuals as a reference, as this number of individuals is found in both the 0.1 ha plots and 1 ha plots. Calculations were made using either EstimateS 9.1.0 (Colwell, 2011) or the R package Vegan

201 (Oksanen et al., 2014). station, or from interpolated climatic maps from Worldclim (Hijmans et al., 2005). We used mean annual 
rainfall as the main climatic variable for subsequent analyses, because it was closely related to all other climate variables, and to AGB and forest attributes. For each site six soil variables were obtained using site coordinates and maps from the Harmonized World Soil Database (Nachtergaele et al., 2012). Data on soil $\mathrm{N}$ and $\mathrm{P}$ were not available from this database. We used CEC (in $\mathrm{cmol} / \mathrm{kg}$ ) as our main soil variable, because it was strongly correlated with the other fertility measures and provides a straightforward measure of soil fertility.

213 AGB and each of the measures of taxonomic and structural attributes within sites for 0.1 ha plots and 1 ha 214 plots. For the 1 ha-level, one correlation was made per site, using all 1-ha plots (with a minimum of 4 215 plots). For the 0.1 ha-level, several correlations were made per site if these small plots were nested within 216 a 1 ha plot and if several 1 ha plots were available. In that case a correlation was made per 1 ha plot using 217 all 0.1 ha subplots nested within the larger 1 ha plot, and this was repeated for all the 1 ha plots.

218 Alternatively, a single correlation was made across all plots at a site, if these small plots were not nested within a single 1 ha plot. To evaluate how general these within-site correlations were, we then calculated at the 0.1 ha and 1 ha level the average and $95 \%$ confidence interval of all of these correlation coefficients combined, pooling all sites. If the $95 \%$ confidence interval did not overlap with zero, this means that, in general, there is a significant correlation between AGB and the variable concerned. We checked the consistency of the results, by repeating this analysis with a mixed linear model in which site was included 224 as a random factor, to account for the nestedness of the data (Appendix S4). For the 0.1 ha plots also the 1 225 ha plot they belonged to was included as a random factor in the model.

227 structural attributes across sites, and therefore across the large-scale environmental gradients. Where data 228 from multiple plots were available at each site we averaged the data per site, to avoid problems with 229 nestedness. For the sites that had both 0.1 ha and 1 ha plots, we only used the average of the 1 ha plots, as 230 they provide more accurate estimates of biomass and diversity. In total, data was available for 59 sites (26 
231 site averages based on 1 ha plots and 33 site averages based 0.1 ha plots). One outlying site with a small

232 plot with exceptionally high AGB was removed from subsequent regression and SEM analyses.

234 Structural equation modelling - We used structural equation modelling (SEM) to test for the direct and

235 indirect effects of climate, soil fertility, and taxonomic and structural attributes on AGB (Fig. 1a). To

236 avoid complexity with nestedness of plots within sites, we based the SEM on average values for 58 sites.

237 Average site values were estimated with a different accuracy. To account for this, sites in the SEM were

238 weighted by the square root of the total plot area per site.

239 To test the conceptual model of Fig .1a, we selected only one variable per "box" (climate, soil,

240 taxonomic attributes, or structural attributes), as we had a limited number of replicates (sites). We used

241 annual rainfall as the climate variable and CEC as the soil variable. Because bivariate scatterplots

242 indicated that AGB and rarefied richness showed a hump-shaped relationship with rainfall, we included

243 for these two response variables both rainfall and rainfall ${ }^{2}$ as predictor variables in the analysis (Fig. 1b),

244 which allows to model such a hump-shaped relationship. The combined effect of rainfall and rainfall ${ }^{2}$ was

245 evaluated by including a composite variable (the oval box in Fig. 1b).

246 Of the three taxonomic attributes considered, we only included rarefied species richness in the

247 SEM, because it is less dependent on plot size, and multiple regressions indicated that it was the best

248 predictor of AGB (data not shown). Of the four structural attributes considered (stand basal area, average

249 tree diameter, number of trees larger than $60 \mathrm{~cm}$ diameter, and stem density), we did a series of SEMs

250 using the same model structure as in Fig. 1a but each time a different structural variable. The models

251 included square root-transformed AGB as the dependent variable, rarefied species richness as an

252 endogenous variable (i.e., a variable that is affected by other variables), and annual rainfall, rainfall ${ }^{2}$, and

253 CEC as exogenous variables (i.e., independent variables that have only an effect on other variables), and

254 the composite variable combining rainfall and rainfall ${ }^{2}$. The only model that significantly fitted the data

255 (i.e., it had a $P$-value larger than 0.05 ) was the model that included average tree diameter as a structural

256 attribute. 

multiplying the standardized coefficients of all paths on one route between one of the exogenous variables and AGB. All SEM analyses were performed in R 3.0.2. The models were specified with variables and paths (the 'arrows' between variables) using the sem function of the lavaan package (Rosseel, 2012). The replicate weights were defined using the svydesign function of the survey package, and the lavaan.survey function was used to evaluate the models when taking replicate weights into account.

\section{Results}

\section{Within-site relations}

266 Within each study site, the AGB of the plots was regressed against the forest attributes. Within most study 267 sites, AGB tended to increase (non-significantly) with species richness, Shannon diversity and rarefied 268 richness for the 0.1 ha plots, whereas there were no clear relationships for the 1 ha plots (Fig. 3). Within 269 each study site, AGB increased consistently with average tree diameter, stand basal area, and large tree 270 density of the plots, both for 0.1 ha and 1 ha spatial scales, whereas tree density was only significant at the 2710.1 ha scale (Fig. 4). The relationship was especially strong between AGB and stand basal area.

To test the generality of these relationships, we conducted a meta-analysis on the value of the 273 correlation coefficient between AGB and each of the predictor variables within each site (Fig. 5, N=103-

274196 correlations for 0.1 ha plots, and $\mathrm{N}=16-17$ correlations for 1 ha plots), and calculated the mean 275 correlation and 95\% confidence intervals. This meta-analysis confirmed that, overall, there was a 276 consistent significant positive relationship between AGB and taxonomic attributes at the 0.1 scale (i.e., the $27795 \%$ confidence interval of the average correlation coefficient did not overlap with zero), whereas this 278 relationship disappeared at the 1 ha scale. Not surprisingly, structural variables such as stand basal area, 279 average tree diameter and the density of large trees are significantly and strongly positively related to 280 AGB at both 0.1 and 1 ha spatial scales (Fig. 5). Similar results were found with a mixed linear model in 281 which site was included as a random factor, to account for the nestedness of the data (Appendix S4). The 
strength of this within-site correlation between AGB and taxonomic diversity/stem density declined with

283 the amount of annual rainfall of the site (Appendix S5).

In addition to testing within sites, we also analyzed whether there were bivariate relationships between AGB, and taxonomic attributes, and structural attributes across our 58 Neotropical forest sites, and thus across large-scale environmental gradients. We selected for this analysis the best scalable measure of diversity (rarefied richness), and one of the best structural predictors of AGB (average tree diameter). Rarefied richness varied 2.7-fold across sites (from 15 to 42 species per 50 stems, Fig. 2b), average tree diameter varied 2.4-fold (from 13 to $32 \mathrm{~cm}$, Fig. 2c) and AGB varied 8.1-fold (from 59 to $479 \mathrm{Mg} / \mathrm{ha}$, Fig. $2922 \mathrm{a})$.

Rarefied richness (Fig. 6a) and AGB (Fig. 6c) showed a hump-backed relationship with annual rainfall and peaked halfway along the rainfall gradient, between 2000 and $3000 \mathrm{~mm} / \mathrm{y}$. Average tree 295 diameter increased continuously with rainfall (Fig. 6b). All three variables tended to decrease with the cation exchange capacity of the soil (Appendix 6), although the relationships were non-significant. AGB was not only related to environmental variables, but also to forest attributes; AGB showed a positive relationship with rarefied richness (Fig. 7a) and average stem diameter (Fig. 7b) across sites.

301 We used structural equation modelling (SEM) to evaluate our conceptual model (Fig. 1a). Our SEM 302 included six variables: annual rainfall, annual rainfall ${ }^{2}$, cation exchange capacity (CEC), rarefied species 303 richness, average stem diameter, and AGB. Average stem diameter was selected as the structural attribute 304 because this was the only accepted model (i.e., it described the data with sufficient accuracy) with $P$-value 305 for the overall model fit larger than 0.05 (Fig. $1 \mathrm{~b} ; \chi^{2}=4.95, \mathrm{P}=0.176 . \mathrm{df}=3$ ), whereas the models were rejected that included basal area $\left(\chi^{2}=23.10, \mathrm{P}<0.001\right)$ or stem density $\left(\chi^{2}=11.80, \mathrm{P}=0.008\right)$. The accepted 
model explained $73 \%$ of the variation in AGB, $15 \%$ of the variation in rarefied richness, and $26 \%$ of the

308

309

310 variation in average stem diameter.

The composite variable 'rainfall+rainfall ${ }^{2}$ ' had the strongest direct effect on AGB (beta=0.67, P < 0.001 ), followed by average stem diameter ( $b e t a=0.26, P=0.001$ ), rarefied richness (beta=0.20, $\mathrm{P}=0.006$ ), and CEC (beta=-0.06, P=0.647) (Table 1, Fig. 1b). Rarefied richness was most strongly affected by rainfall+rainfall ${ }^{2}$ (beta=0.39, $\mathrm{P}=0.037$ ), and average diameter was most strongly affected by the linear effect of rainfall (beta=0.49, $\mathrm{P}=0.018$ ). The linear effect of rainfall had, via average diameter, the strongest indirect effect on AGB (beta=0.129; Appendix S7).

\section{Discussion}

Tropical forests store a significant part of global carbon and biodiversity, and the question is whether this biodiversity is relevant for carbon storage? We related above-ground biomass (AGB) to forest attributes and environmental drivers, and found that taxonomic attributes had the strongest relationships with AGB at small spatial scales (0.1 ha), whereas structural attributes had strong relationships with AGB at both spatial scales (0.1 and 1 ha). Species richness had an independent, positive effect on AGB at local scales, and when sites across the continent were compared. We discuss the implications of these results for conservation and REDD+ activities.

\section{Taxonomic attributes have the strongest relationships with AGB at small spatial scales}

We hypothesized that species richness and diversity would have a positive effect on biomass through niche complementarity, the selection effect or the insurance effect, and that these effects would be observed especially within sites at a small spatial scale (where the species richness value is low because of the small sample area) but not at larger spatial scale (because of species redundancy). Indeed, within sites we found positive relationships between AGB and taxonomic diversity measures at the 0.1 ha but not at 
333 the 1 ha scale (Fig. 5). The relationship was strongest for area-based diversity measures (richness) and the 334 weakest for Shannon diversity and rarefied species richness (Fig. 5), indicating that variation in stem 335 density among plots partly drives the AGB-diversity relation. Similarly, in a global analysis of larger 336 forest plots (>16 ha), Chisholm et al. (2013) also found that diversity-biomass relationships were always 337 strong and positive at very small spatial scales $(20 \times 20 \mathrm{~m})$, whereas at larger spatial scales $(0.25$ ha and 1 338 ha) there was no consistent relationship. Higher species richness enhances the variation in species traits 339 found in the community leading to niche complementarity, a higher resource capture, more efficient 340 resource use, and higher productivity. Higher species richness may also enhance facilitation (e.g., where

341 for example a nitrogen fixing species enhances soil fertility, and through this the productivity of the other

342 species). Higher species richness also increases the chance of a selection effect (in which a highly

343 productive or large species that stores a lot of biomass is included in the stand).

344 It should be acknowledged that 0.1 ha plots are rather small to accurately estimate biomass: in 345 some forests this plot size will include very few trees, or an emergent tree. This may strongly affect the 346 biomass estimate, and partly explain the large scatter in AGB at a given site. Hence, within-site 347 relationships between taxonomic diversity and AGB may be partly affected by gap dynamics and cyclic 348 succession: just after disturbance there may be a low tree species richness and biomass in the gap, whereas 349 with patch development both the number of species and their biomass increase over time, in line with the 350 intermediate disturbance hypothesis (Connell, 1978). Alternatively, the relationship between diversity and 351 AGB within sites may be driven by more permanent local environmental gradients, where areas with 352 adverse conditions, such as shallow soils (e.g., Emilio et al., 2014), rocky outcrops, waterlogged areas or 353 ridge tops exposed to intense winds contain fewer stems, fewer species and lower biomass than areas with 354 deep well-developed humid and fertile soils.

357 We expected that greater tree density and basal area of the forest would lead to an increase in AGB, as 358 structure positively influences biomass, but we did not know their relative importance. We found that 
within sites, AGB moderately increased with increasing tree density, more strongly with large tree density and most strongly with stand basal area (Fig. 5). AGB variation across forest plots is a function of the stem density, and the mean stem diameter, height, crown area and wood density of trees. Biomass increases exponentially with tree diameter, and large trees therefore contribute disproportionally to stand biomass compared to small trees. This explains why average tree diameter, large tree density and stand basal area are better predictors of AGB than overall tree density. A recent Pantropical analysis for 120 lowland tropical forests (Slik et al., 2013) showed that 70\% of the site variation in AGB was determined by the density of large trees ( $>70 \mathrm{~cm}$ diameter at breast height). Because of the paucity of large trees, Neotropical forest contained ca. 30\% less biomass when compared to Paleotropical forests. Large trees play an important role in ecosystem functioning, not only because they contribute most AGB but also because they form the forest canopy, where most of the photosynthetic carbon gain is concentrated. These

370 large trees possess large and well-lit crowns, and therefore contribute most to forest primary productivity

371 (Stephenson et al., 2014).

Rainfall is a stronger driver of $A G B$ and biodiversity than is soil fertility

374 We hypothesized that with an increase in plant water availability (rainfall) and nutrient availability (CEC)

375 there would be an increase in AGB (Fig. 1a), whereas at very high rainfall levels we would expect that 376 soils would be highly weathered and leached (e.g., Swaine, 1996), leading to a decline in AGB. We indeed

377 found that AGB showed a unimodel relationship with the rainfall gradient across sites (Fig. 6c). Our 378 results were not due to the equations used (moist forest equations predict a higher biomass than dry and 379 wet forest equations) because when we tested this effect using the same moist forest equation for all plots, 380 then the same unimodal relationship was found (Appendix S8). In our case, the decline in AGB at high 381 rainfall was not due to leaching, as there was no relationship between rainfall and CEC in our dataset 382 (Pearson $\mathrm{r}=0.02, \mathrm{n}=60, \mathrm{P}=0.866$ ). A negative relationship between rainfall and soil fertility might be 383 found in geologically relatively homogeneous areas (Swaine, 1996). At the spatial scale of our study 384 across distant Neotropical forest sites, however, there is a large variation in ecological and geological 
history, and parent rock material (cf. Stropp et al., 2009), which may override more subtle relationships between soils and rainfall.

Reasons for the decline of AGB at high rainfall may be due to reduced insolation because of cloud cover (Graham et al., 2003), or due to species composition and forest structural attributes. At intermediate rainfall levels, forests are more likely to be dominated by tall and large-diameter drought-deciduous canopy trees that contribute a large amount of biomass whereas at higher rainfall levels forests are more dominated by shorter-statured slender trees that better compete and persist in dense and shaded closedcanopy forest before they are able to access the canopy (Hall \& Swaine, 1981; Fauset et al., 2012). At low rainfall, AGB declined, indicating that low water availability and/or a shorter length of the growing season may constrain tree stature (probably because of hydraulic limitation) and tree growth (Toledo et al., 2011), and hence AGB stocks. It should be noted that at the same rainfall level there is a large variation in AGB across forest sites (Fig. 6c) indicating that rainfall may set an upper limit to biomass stocks, but that other factors (topography, shallow soils or rocky soils) may constrain biomass from reaching their potential maximum value. Apart from rainfall, other climatic features that determine plant water availability, such as length or severity of the dry season may explain additional variation in AGB. showed a non-significant decrease with increased CEC (our indicator of soil fertility, Appendix S6), and

402 CEC was neither significant in the multivariate structural equation model (Fig. 1b). Interestingly, Quesada et al. (2012) found that forest AGB in the Amazon decreased with potassium concentration, which is one of the cations that contributes to CEC. However, they also found that total available phosphorous was by far the best predictor of AGB in their study, and that P had a positive effect on AGB and biomass productivity. This is in line with the widely held idea that $\mathrm{P}$ limits productivity and biomass in tropical (Vitousek et al., 2010; but see Santiago et al., 2012). It should be stressed that AGB is a state variable that reflects the outcome of various underlying factors that affect biomass production, retention and loss.

409 Biogeographical patterns in species traits (such as maximum height, tree longevity and wood density) 410 determine biomass retention (Slik et al., 2013; Fauset et al., 2015); whereas recent local disturbance 
411 history may determine biomass loss. As a result, the observed bivariate relationship between biomass and

412 any other variable is location- and scale-dependent, may be weaker than expected, and may have different

413 ultimate causes. For example, the tendency for a negative relationship between AGB and CEC that we

414 observed is not driven by a higher productivity in areas with poor soils, but likely by species having

415 adaptations to local soil conditions that enhance longevity at the species level (high WD, long lifespan),

416 and therefore biomass retention and the buildup of a larger biomass pool at the stand level (Baker et al.,

417 2009).

418

$419 A G B$ is most strongly driven by rainfall, followed by structural attributes, and taxonomic attributes

420 We used structural equation modelling to test the independent effects of taxonomic and structural

421 attributes on AGB, and to evaluate the relative importance of biotic and environmental drivers of AGB

422 variation across sites. Standardized path coefficients indicate that AGB is most strongly driven by the

423 direct and indirect effects of rainfall (Table 1, Appendix S7, Fig. 1b), followed by average stem diameter

424 and rarefied richness, whereas CEC had a negligible effect (Fig. 1b).

425 At this continental scale, rainfall was a much stronger driver of AGB than our indicator of soil

426 fertility (CEC). It should be stressed that this may partly be the result of methodological constraints; we

427 did not use data on soil conditions at each site and for each plot, but instead used a global soil database to

428 infer soil fertility and we did not consider other nutrients, such as P. Yet, it also may indicate that rainfall

429 constrains productivity and AGB at large spatial scales, whereas soil fertility may become more important

430 at regional (Quesada et al., 2012) and local scales (Laurance et al., 1999).

431 Rarefied species richness has a clear, independent and positive effect on AGB at this continental

432 scale, once other structural and environmental drivers have been taken into account. To our knowledge,

433 this is the first large-scale study analyzing the multivariate relationships between AGB and its drivers

434 (environment and forest attributes) and demonstrating that biodiversity has an independent positive effect

435 on AGB of highly diverse tropical forests. Most empirical studies that have examined biodiversity effects

436 on forest AGB or productivity have ignored the effect of forest structure (e.g., Gamfeldt et al., 2012), the 
438 single subtropical forest site that during succession diversity had an independent, positive effect on plot

439 basal area growth. Our study shows that the findings from experimental studies, temperate grasslands and 440 relatively simple temperate forests that biodiversity matters for ecosystem functioning, can therefore also

441 be extended to structurally complex, and hyperdiverse tropical forests that contain as many as $15-42$

442 species per 50 stems (Appendix S1) .

443 We used a structural equation modeling approach to control as well as possible for other

444 potentially confounding factors, but correlation does not necessarily mean causation. Controlled

445 experiments (e.g., Hector et al., 2011), and modeling studies (e.g., Sakschewski et al., 2015) are needed to

446 provide further support for a causal relationship between biodiversity and carbon storage in the tropics.

447 Our study shows that the biodiversity effect is sufficiently strong to be picked up in the real world, and to 448 be ecologically relevant.

Implications for carbon storage and REDD+

451 We have shown that AGB is related to the environment, as well as to structure and diversity of the forest, 452 and these results have three important implications for carbon storage in tropical forest, and the REDD+ 453 program.

454 First, our results show that rainfall is the most important driver of AGB, and that AGB peaks in 455 the middle of the rainfall gradient. If AGB also scales closely with belowground biomass then this result 456 implies that, in terms of carbon storage, potential gains from REDD programs are highest in tropical moist 457 forests as these forests occur at intermediate rainfall, and store the largest amount of biomass (Fig. 2). So 458 for REDD+, forest conservation, restoration or reforestation could best be concentrated in these areas. 459 The hump-backed relationship between AGB and rainfall means that any decrease in rainfall will have 460 different repercussions for long-term carbon storage in wet and dry forests. In currently wet forests, a 461 decline in rainfall may lead in the long-term to higher AGB (e.g., Fauset et al., 2012), whereas in currently 462 moist and dry forest it may lead to lower AGB. 

to AGB at all spatial scales assessed; from small spatial scales (Fig. 4) up to large spatial scales across the continent (Fig. 1b,7). Structural attributes have the advantage that they can easily be measured in the field by local communities, or assessed using remote sensing techniques. By using remote sensing techniques one can easily scale up field data and produce spatially continuous AGB information over large areas

468 (Baccini et al., 2012), thus providing a better assessment of global carbon storage, deforestation and forest 469 degradation, and providing benchmark maps for REDD+ monitoring reporting and verification activities.

470 Although remote sensing maps hold great promise, they may fail to capture regional gradients in biomass

471 that are driven by other forest attributes, such as forest height and wood density (Mitchard et al., 2014).

472 By linking field data to remote sensing derived structural indices, one may map and detect large-scale 473 patterns in AGB while maintaining local realism.

474 A third implication for REDD+ is that areas with high diversity also tend to have a high biomass

475 (Fig. 7a), indicating that areas with a high carbon storage potential also have a high conservation potential.

476 Moreover, species richness has an independent and positive effect on AGB (Fig. 1b). Species richness 477 may also buffer ecosystem productivity against environmental change (Isbell et al., 2011), and enhance 478 ecosystem resilience to disturbance (Diaz et al., 2009). We found that rarefied species richness had a 479 direct effect on forest biomass, despite the very large number of species found in these hyperdiverse 480 tropical forests. The fact that in this study diversity co-determines forest functioning, indicates that the conservation of biodiversity should not be considered as a simple co-benefit of REDD+ (Diaz et al., 2009), but as an integral and crucial component of all REDD activities.

\section{Concluding remarks}

485 To our knowledge, this is the first study to show the relative importance of environmental conditions and 486 structural and taxonomic attributes for the amount of above ground biomass of highly diverse tropical 487 forests across large spatial scales. AGB is mainly driven by rainfall, followed by structure and species 488 richness. Species richness has an independent positive effect on AGB. From the perspective of REDD+, 
biodiversity conservation is therefore not only a goal by itself, but it will also help to increase carbon

490 storage. Hence, conserving biodiversity is a win-win strategy because biodiversity is crucial for forest

491 functioning.

\section{Acknowledgements}

494

We gratefully thank all the people that have established and measured the plots, and the institutions and funding agencies that supported them (e.g., CONACyT, the Darwin Initiative). This study was partly funded by European Union's Seventh Framework Programme ([FP7/2007-2013]) under grant agreement $\mathrm{n}^{\circ}$ 283093; Role Of Biodiversity In climate change mitigatioN (ROBIN). We thank Nick Brokaw, Rick Condit, Robin Foster, Steve Hubbell, Joe Wright and Jess Zimmerman for kindly allowing us to use their (plot) data, Joe Wright and two anonymous reviewers for their very helpful comments on the manuscript, and James Grace and Daniel Laughlin for their helpful advice on the SEM analysis. The Chamela plot was supported by the ReserBos project (SEP-CONACyT/2009-129740). The Luquillo forest dynamics plot was supported by Luquillo Long Term Ecological Research program (LTER), USA National Science Foundation and others. The BCI 50-ha plot was organized by S.P. Hubbell, R.B. Foster, R. Condit, S. Lao, and R. Perez under the Center for Tropical Forest Science and the Smithsonian Tropical Research in Foundation, and hundreds of field workers have contributed.

\section{References}

512 Baccini, A., Goetz, S. J., Walker, W. S., Laporte, N. T., Sun, M., Sulla-Menashe, Hackler, J., Beck, 
dioxide emissions from tropical deforestation improved by carbon-density maps. Nature Climate Change, 2, 182-185.

Baker, T. R., Phillips, O. L., Laurance, W. F., Pitman, N. C. A., Almeida, S., Arroyo, L., Difiore, A.,

Erwin, T., Higuchi, N., Killeen, T. J., Laurance, S. G., Nascimento, H., Monteagudo, A., Neill, D. A., Silva, J. N. M., Malhi, Y., López Gonzalez, G., Peacock, J., Quesada, C. A., Lewis, S. L., \& Lloyd, J. (2009) Do species traits determine patterns of wood production in Amazonian forests? Biogeosciences, 6, 297-307.

Baraloto, C., Rabaud, S., Molto, Q., Blanc, L., Fortunel, C., Hérault, B., Dávila, N., Mesones, I., Rios, M., Valderrama, E. \& Fine, P.V. A. (2011) Disentangling stand and environmental correlates of aboveground biomass in Amazonian forests. Global Change Biology, 17, 2677-2688.

Baruffol, M., Schmid, B., Bruelheide, H., Chi, X., Hector, A., Ma, K., Michalski, S., Tang, Z. \& Niklaus, P.A. (2013) Biodiversity Promotes Tree Growth during Succession in Subtropical Forest. PLoS ONE, 8, e81246.

Beer C, Reichstein, M., Tomelleri, E., Ciais, P., Jung, M., Carvalhais, N., Rödenbeck, C., Arain, M.A., Baldocchi, D., BOnan, G.B., Bondeau, A., Cescatti, A., Lasslop, G., Lindroth, A., Lomas, M., Luyssaert, S., Margolis, H., Oleson, K.W., Roupsard, O., Veenendaal, E., Viovy, N., Williams, C., Woodward, F.I. \& Papale, D. (2010) Terrestrial Gross Carbon Dioxide Uptake: Global Distribution and Covariation with Climate. Science, 329, 834-838.

Bonan GB (2008) Forests and climate change: Forcings, feedbacks, and the climate benefits of forests. Science, 320, 1444-1449.

Cardinale, B.J., Matulich, K.L., Hooper, D.U., Byrnes, J.E., Duffy, E., Gamfeldt, L., Balvanera, P., O’Connor, M.I. \& Gonzalez, A. (2011) The functional role of producer diversity in ecosystems. American Journal of Botany, 98, 572-92.

Cavanaugh, K.C., Gosnell, J.S., Davis, S.L., Ahumada, J., Boundja, P., Clark, D.B., Mugerwa, B., Jansen, P. a., O’Brien, T.G., Rovero, F., Sheil, D., Vasquez, R. \& Andelman, S. (2014) Carbon storage in 
tropical forests correlates with taxonomic diversity and functional dominance on a global scale. Global Ecology and Biogeography, 23, 563-573.

Chave, J., Andalo, C., Brown, S., Cairns, M. A., Chambers, J. Q., Eames, D. Folster, H., Formard, F., T. (2005) Tree allometry and improved estimation of carbon stocks and balance in tropical forests. Oecologia, 145, 87-99.

Chisholm, R.A., Muller-Landau, H.C., Abdul Rahman, K., Bebber, D.P., Bin, Y., Bohlman, S.A., Bourg, N.A., Brinks, J., Bunyavejchewin, S., Butt, N., Cao, H., Cao, M., Cárdenas, D., Chang, L.-W., Chiang, J.-M., Chuyong, G., Condit, R., Dattaraja, H.S., Davies, S., Duque, A., Fletcher, C., Gunatilleke, N., Gunatilleke, S., Hao, Z., Harrison, R.D., Howe, R., Hsieh, C.-F., Hubbell, S.P., Itoh, A., Kenfack, D., Kiratiprayoon, S., Larson, A.J., Lian, J., Lin, D., Liu, H., Lutz, J.A., Ma, K., Malhi, Y., McMahon, S., McShea, W., Meegaskumbura, M., Mohd. Razman, S., Morecroft, M.D., Nytch, C.J., Oliveira, A., Parker, G.G., Pulla, S., Punchi-Manage, R., Romero-Saltos, H., Sang, W., Schurman, J., Su, S.-H., Sukumar, R., Sun, I-F., Suresh, H.S., Tan, S., Thomas, D., Thomas, S., Thompson, J., Valencia, R., Wolf, A., Yap, S., Ye, W., Yuan, Z. \& Zimmerman, J.K. (2013) Scale-dependent relationships between tree species richness and ecosystem function in forests. Journal of Ecology, 101, 1214-1224.

Colwell, R.K. (2011) Estimates: Statistical Estimation of Species Richness and Shared Species from Samples. Version 9. 2011. User's Guide and application published at http://purl.oclc.org/estimates

Connell, J.H. (1978) Diversity in tropical rain forests and coral reefs. Science, 199, 1302-1310.

Diaz, S., Hector, A. \& Wardle, D.A. (2009) Biodiversity in forest carbon sequestration initiatives: not just a side benefit. Current Opinion in Environmental Sustainability, 1, 55-60.

Emilio, T., C. A. Quesada, F. R. Costa, W. E. Magnusson, J. Schietti, T. R. Feldpausch, R. J. Brienen, T. R. Baker, J. Chave, \& E. Álvarez. (2014). Soil physical conditions limit palm and tree basal area in Amazonian forests. Plant Ecology \& Diversity, 7, 215-229. 
Fauset, S., Baker, T.R., Lewis, S.L., Feldpausch, T.R., Affum-Baffoe, K., Foli, E.G., Hamer, K.C. \& Swaine, M.D. (2012) Drought-induced shifts in the floristic and functional composition of tropical forests in Ghana. Ecology Letters, 15, 1120-1129.

Fauset, S.; Johnson, M.O., Gloor, M., Baker, T.R., Monteagudo, A.M., Brienen, R.J.W., Feldpausch, T.R et al. (2015) Hyperdominance in Amazonian forest carbon cycling. Nature Communications doi: $10.1038 /$ ncomms 7857

Fine, P. V. A., Ree, R. H., Burnham, R. J. (2008) The disparity in tree species richness among tropical, temperate, and boreal biomes: the geographical area and age hypothesis. Pp 31-45 in Carson, R. P., \& Schnitzer, S. A. (eds.) Tropical Forest Community Ecology. Blackwell, Oxford, UK.

Gamfeldt, L., Snäll T., Bagchi, R., Jonsson, M., Gustafsson, L., Kjellander, P., Ruiz-Jaen, M.C., Fröberg, M., Stendahl, J., Philipson, C.D., Mikusiński, G., Andersson, E., Westerlund, B., Andrén, H., Moberg, F., Moen, J. \& Bengtsson, J. (2013) Higher levels of multiple ecosystem services are found in forests with more tree species. Nature Communications, 4, Art. 1340.

Graham, A. E., Mulkey, S. S., Kitajima, K., Phillips, N. G.\& Wright, S. J. (2003) Cloud cover limits net $\mathrm{CO}_{2}$ uptake and growth of a rainforest tree during tropical rainy seasons. Proceedings of the National Academy of Sciences of the United States of America, 100, 572-576.

Hall, J.B. \& Swaine, M.D. (1981) Distribution and ecology of vascular plants in tropical rainforest: forest vegetation in Ghana. The Hague (the Netherlands): Dr W. Junk Publishers.

Hansen, M.C., DeFries, R.S., Townshend, J.R.G., Carroll, M. \& Dimiceli, C. (2003) Global percent tree cover at a spatial resolution of 500 meters: First results of the MODIS vegetation continuous fields algorithm. Earth Interactions, 7, 1-15.

Hector, A., Philipson, C., Saner, P., Chamagne, J., Dzulkifli, D., O'Brien, M., Snaddon, J.L., Ulok, P., Weilenmann, M., Reynolds, G. \& Godfray, H.C.J. (2011) The Sabah Biodiversity Experiment: a long-term test of the role of tree diversity in restoring tropical forest structure and functioning. Philosophical Transactions of the Royal Society, 366, 3303-3315. 
589

590

591

592

593

594

595

596

597

598

599

600

601

602

603

604

605

606

607

608

609

610

611

612

613

614

Hijmans, R.J., S.E. Cameron, J.L. Parra, P.G. Jones \& Jarvis, A. (2005) Very high resolution interpolated climate surfaces for global land areas. International Journal of Climatology, 25, 1965-1978.

Isbell, F., Calcagno, V., Hector, A., Connolly, J., Harpole, W.S., Reich, P.B., Scherer-Lorenzen, M., Schmid, B., Tilman, D., van Ruiven, J., Weigelt, A., Wilsey, B.J., Zavaleta, E.S. \& Loreau, M. (2011) High plant diversity is needed to maintain ecosystem services. Nature, 477, 199-202.

Laurance, W.F., Fearnside, P.M., Laurance, S.G., Delamonica, P., Lovejoy, T.E., Rankin-de Merona, J.M., Chambers, J.Q. \& Gascon, C. (1999) Relationship between soils and Amazon forest biomass: a landscape-scale study. Forest Ecology and Management, 118, 127-138.

Lohbeck, M., Poorter, L., Martínez-Ramos, M. \& Bongers, F. (2015) Biomass is the main driver of changes in ecosystem process rates during tropical forest succession. Ecology, 96, 1242-1252.

Loreau, M. \& Hector, A. (2001) Partitioning selection and complementarity in biodiversity experiments. Nature, 412, 72-76.

Malhi, Y., Baker, T.R., Phillips, O.L., Almeida, S., Alvarez, E., Arroyo, L., Chave, J., Czimczik, C.I., Fiore, A. Di, Higuchi, N., Killeen, T.J., Laurance, S.G., Laurance, W.F., Lewis, S.L., Montoya, L.M.M., Monteagudo, A., Neill, D. a., Vargas, P.N., Patino, S., Pitman, N.C. a., Quesada, C.A., Salomao, R., Silva, J.N.M., Lezama, A.T., Martinez, R.V., Terborgh, J., Vinceti, B. \& Lloyd, J. (2004) The above-ground coarse wood productivity of 104 Neotropical forest plots. Global Change Biology, 10, 563-591.

Mitchard, E.T.A., Feldpausch, T.R., Brienen, R.J.W. et al. (2014). Markedly divergent estimates of Amazon forest carbon density from ground plots and satellites. Global Ecology and Biogeography, 23, 935-946.

Nachtergaele, F., van Velthuizen, H., Verelst, L. \& Wiberg, D. (2012) Harmonized World Soil Database version 1.2. FAO, Rome and IIASA, Laxenburg, Austria.

Naeem, S., Bunker, D.E., Hector, A., Loreau, M. \& Perrings, C. (2009) Biodiversity, ecosystem functioning, and human wellbeing. An ecological and economic perspective. Oxford University press, Oxford. 
Oksanen, J., Blanchet, F.G., Kindt, R., Legendre, P., Minchin, R., O’Hara, R.B., Simpson, G.L., Solymos, P., Stevens, M. H. H. \& Wagner, H. (2014) Package vegan: Community ecology package. R package version 2.2-0. http://cran.r-project.org/web/packages/vegan/.

Paquette, A. \& Messier, C. (2011) The effect of biodiversity on tree productivity: from temperate to boreal forests. Global Ecology and Biogeography, 20, 170-180.

Pearson, R., Walker, S. \& Brown, S. (005) Source book for land use, land-use change and forestry projects. World Bank, Washington.

Quesada, C.A., Phillips, O.L., Schwarz, M., Czimczik, C.I., Baker, T.R., Patiño, S., Fyllas, N.M., Hodnett, M.G., Herrera, R., Almeida, S., Alvarez Dávila, E., Arneth, A., Arroyo, L., Chao, K.J., Dezzeo, N., Erwin, T., di Fiore, A., Higuchi, N., Honorio Coronado, E., Jimenez, E.M., Killeen, T., Lezama, a. T., Lloyd, G., López-González, G., Luizão, F.J., Malhi, Y., Monteagudo, A., Neill, D. a., Núñez Vargas, P., Paiva, R., Peacock, J., Peñuela, M.C., Peña Cruz, A., Pitman, N., Priante Filho, N., Prieto, A., Ramírez, H., Rudas, A., Salomão, R., Santos, a. J.B., Schmerler, J., Silva, N., Silveira, M., Vásquez, R., Vieira, I., Terborgh, J. \& Lloyd, J. (2012) Basin-wide variations in Amazon forest structure and function are mediated by both soils and climate. Biogeosciences, $\mathbf{9}$, $2203-2246$.

Rosseel, Y. (2012) lavaan: an R package for structural equation modeling. Journal of Statistical Software, 48, $1-36$.

Sakschewski, B., von Bloh, W., Boit, A., Rammig, A., Kattge, J., Poorter, L., Peñualeas, J., Thonicke, K. (2015) Leaf and stem economics spectra drive diversity of functional plant traits in a dynamic global vegetation model. Global Change Biology, 21, 2711-2725.

Santiago, L. S., Wright, S. J., Harms, K. E., Yavitt, J. B., Korine, C., Garcia, M. N. \& Turner, B. L. (2012). Tropical tree seedling growth responses to nitrogen, phosphorus and potassium addition. Journal of Ecology, 100, 309-316.

Slik, J.W.F, Paoli, G., McGuire, K., Amaral, I., Barroso, J., Bastian, M., Blanc, L., Bongers, F., Boundja, P., Clark, C., Collins, M., Dauby, G., Ding, Yi, Doucet, J., Eler, E., Ferreira, L., Forshed, O., 
Fredriksson, G., Gillet, J., Harris, D., Leal, M., Laumonier, Y., Malhi, Y., Mansor, A., Martin, E., Miyamoto, K., Araujo-Murakami, A., Nagamasu, H., Nilus , R., Nurtjahya, E., Oliveira, Á., Onrizal, O., Parada-Gutierrez, A., Permana, A., Poorter, L., Poulsen, J., Ramirez-Angulo, H., Reitsma, J., Rovero, F., Rozak, A., Sheil, D., Silva-Espejo, J., Silveira, M., Spironelo, W., Steege, H., Stevart, T., Navarro-Aguilar, G.E., Sunderland, T., Suzuki, E., Tang, J., Theilade, I., van der Heijden, G., van Valkenburg, J., Van Do, T., Vilanova, E., Vos, V., Wich, S., Wöll, H., Yoneda, T.i, Zang, R.O, Zhang, M.G. \& Zweifel, N. (2013). Large trees drive forest aboveground biomass variation in moist lowland forests across the tropics Global Ecology and Biogeography, 22, 12611271.

Stephenson, N.L., Das, a. J., Condit, R., Russo, S.E., Baker, P.J., Beckman, N.G., Coomes, D. a., Lines, E.R., Morris, W.K., Rüger, N., Álvarez, E., Blundo, C., Bunyavejchewin, S., Chuyong, G., Davies, S.J., Duque, Á., Ewango, C.N., Flores, O., Franklin, J.F., Grau, H.R., Hao, Z., Harmon, M.E., Hubbell, S.P., Kenfack, D., Lin, Y., Makana, J.-R., Malizia, A., Malizia, L.R., Pabst, R.J., Pongpattananurak, N., Su, S.-H., Sun, I.-F., Tan, S., Thomas, D., van Mantgem, P.J., Wang, X., Wiser, S.K. \& Zavala, M.A. (2014) Rate of tree carbon accumulation increases continuously with tree size. Nature, 507, 90-93.

Stropp, J., Ter Steege, H. \& Malhi, Y. (2009) Disentangling regional and local tree diversity in the Amazon. Ecography, 32, 46-54.

Swaine, M. D. (1996) Rainfall and soil fertility as factors limiting forest species distributions in Ghana. Journal of Ecology, 84, 419-428.

Ter Steege, H., Pitman, N., Sabatier, D., Castellanos, H., van der Hout, P., Douglas, C., Silveira, M., Phillips, O., Vasquez, R., van Andel, T., Duifenvoorden, J., de Oliveira, A. adalardo, Ek, R., Lilwah, R., Thomas, R., van Essen, J., Baider, C., Maas, P., Mori, S., Terborgh, J., Vargas, P.N., Mogollon, H. \& Morawetz, W. (2003) A spatial model of tree a-diversity and tree density for the Amazon. Biodiversity and Conservation, 12, 2255-2277. 
666

667

668

669

670

671

672

673

674

675

676

677

678

679

680

681

682

683

684

685
Tilman, D., Reich P.B., Knops, J., Wedin, D., Mielke, T. \& Lechman, C. (2001) Diversity and productivity in a long-term grassland experiment. Science, 294, 843-845.

Toledo, M., Poorter, L., Peña-Claros, M., Alarcón, A., Balcázar, J., Leaño, C., Licona, J.C., Llanque, O., Vroomans, V., Zuidema, P. \& Bongers, F. (2011) Climate is a stronger driver of tree and forest growth rates than soil and disturbance. Journal of Ecology, 99, 254-264.

Vilà, M., Carillo-Gavilán, A., Vayreda, J., Bugmann, H., Fridman, J., Grodzki, W., Haase, J., Kunstler, G., Schelhaas, M.J. \& Trasobares. (2013) Disentangling biodiversity and climatic determinants of wood production. PLOSone, $\mathbf{8}$, e53530.

Vitousek, P.M., Porder, S., Houlton, B.Z. \& Chadwick, O.A. (2010) Terrestrial phosphorus limitation: mechanisms, implications, and nitrogen-phosphorus interactions. Ecological Applications, 20, 515.

Yachi, S. \& Loreau, M. (1999) Biodiversity and ecosystem productivity in a fluctuating environment: The insurance hypothesis. Proceedings of the National Academy of Sciences, 96, 1463-1468.

Zanne, A.E., Lopez-Gonzalez, G., Coomes, D.A., Ilic, J., Jansen, S., Lewis, S.L., Miller, R.B., Swenson N.G., Wiemann M.C. \& Chave, J. (2009) Data from: Towards a worldwide wood economics spectrum. Dryad Digital Repository. http://dx.doi.org/10.5061/dryad.234.

Zhang, Y., Chen, H.Y.H. \& Reich, P.B. (2012) Forest productivity increases with evenness, species richness and trait variation: a global meta-analysis. Journal of Ecology, 100, 742-749. 


\section{Biosketch}

687 This data analysis was carried out as a collaborative research effort amongst people of the EU-funded

688 ROBIN project (the ROle of Biodiversity In climate change mitigatioN) and other forest researchers with

689 interest in the diversity and dynamics of tropical forests. We hope that such a large-scale comparative

690 approach provides a better insight into the functioning of these forests. 
692 Table 1: The results of the structural equation model shown in Fig. 1b. Unstandardized coefficient, standard error, Z693 value, P-value and standardized coefficient are given for each path (i.e., each arrow in Fig. 1b). These statistics are 694 given for the composite variable, the regressions between the remaining variables, and the intercepts and error 695 variances of the three dependent variables (above-ground biomass [AGB], rarefied richness and average diameter).

696 The model was accepted $\left(\chi^{2}=4.95, \mathrm{P}=0.176\right.$ ), had 3 degrees of freedom (note that this based on the number of 697 'knowns' minus the number of free parameter in the model, not on the sample size).

\section{Response variable Predictor variable Coefficient Std.error Z-value P-value Std.Coefficient} Composite variable:

Rainfall+Rainfall ${ }^{2}$

Regressions:

$\operatorname{sqrt}(\mathrm{AGB})$

Rarefied richness

Average diameter
Rainfall

Rainfall $^{2}$

Rainfall+Rainfall $^{2}$

$\ln$ (CEC)

Rarefied richness

Average diameter

Rainfall+Rainfall $^{2}$

$\ln$ (CEC)

Rainfall

$\ln (\mathrm{CEC})$
4.44

$-0.80$

2.61

$-0.19$

0.09

0.39

3.19

0.32

1.21

0.08
0.28

0.41

0.04

0.12

1.53

0.83

0.51

0.33
4.76

$-26.15<0.001-4.56$

$9.24<0.001 \quad 0.67$

$\begin{array}{lll}-0.46 & 0.647 & -0.06\end{array}$

$\begin{array}{lll}2.73 & 0.006 & 0.20\end{array}$

$\begin{array}{lll}3.36 & 0.001 & 0.26\end{array}$

$\begin{array}{lll}2.08 & 0.037 & 0.39\end{array}$

$\begin{array}{lll}0.38 & 0.702 & 0.05\end{array}$

$\begin{array}{lll}2.37 & 0.018 & 0.49\end{array}$

$\begin{array}{lll}0.24 & 0.813 & 0.04\end{array}$ 
700 Figure 1 (a). Conceptual diagram showing how environmental drivers (rainfall, soil fertility) affect forest attributes (taxonomic and structural attributes), and how environmental drivers and forest attributes together affect carbon storage in above-ground biomass (AGB). The two types of forest attributes are characterized by their magnitude (e.g., species richness, basal area) and their variation (e.g., species diversity, density of large trees). (b) Final structural equation model relating AGB to biotic drivers

705 (rarefied richness and average tree diameter [average $\mathrm{dbh}$ ) and abiotic drivers (rainfall and cation exchange capacity [CEC]). Biomass and rarefied richness show a hump-backed relationship with rainfall (see also Fig. 6a,c), and are therefore modeled as a function of rainfall and the square of rainfall (rainfall ${ }^{2}$ ). Significant paths (continuous arrows), non-significant paths (broken arrows) and correlations (doublesided arrows) are shown. For each path the significance level (P) and standardized regression coefficient are shown. $\mathrm{R}^{2}$ indicates the total variation in a dependent variable that is explained by the combined 711 independent variables.

\section{Environmental drivers \\ Forest attributes \\ Carbon}

a)

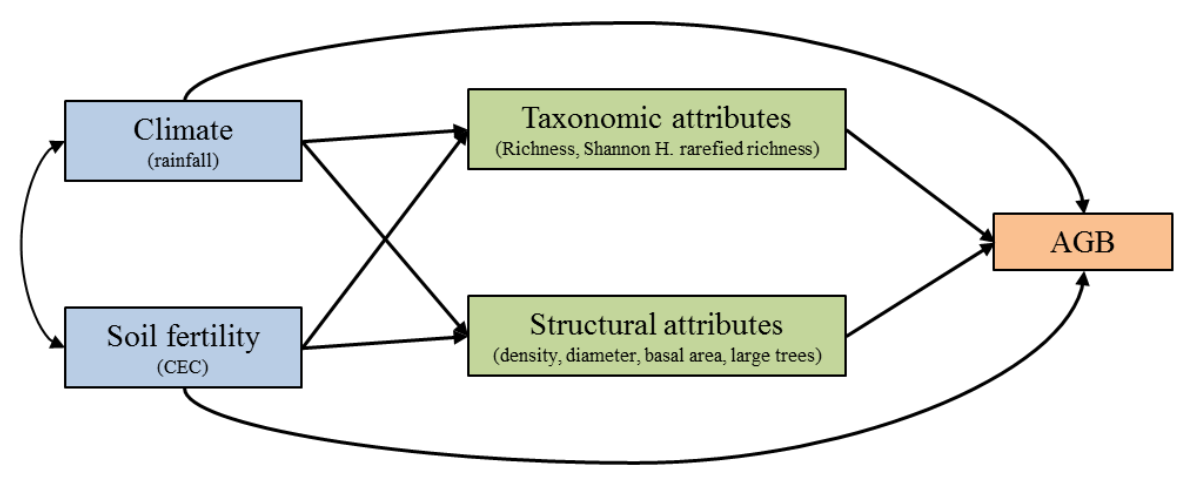

b)

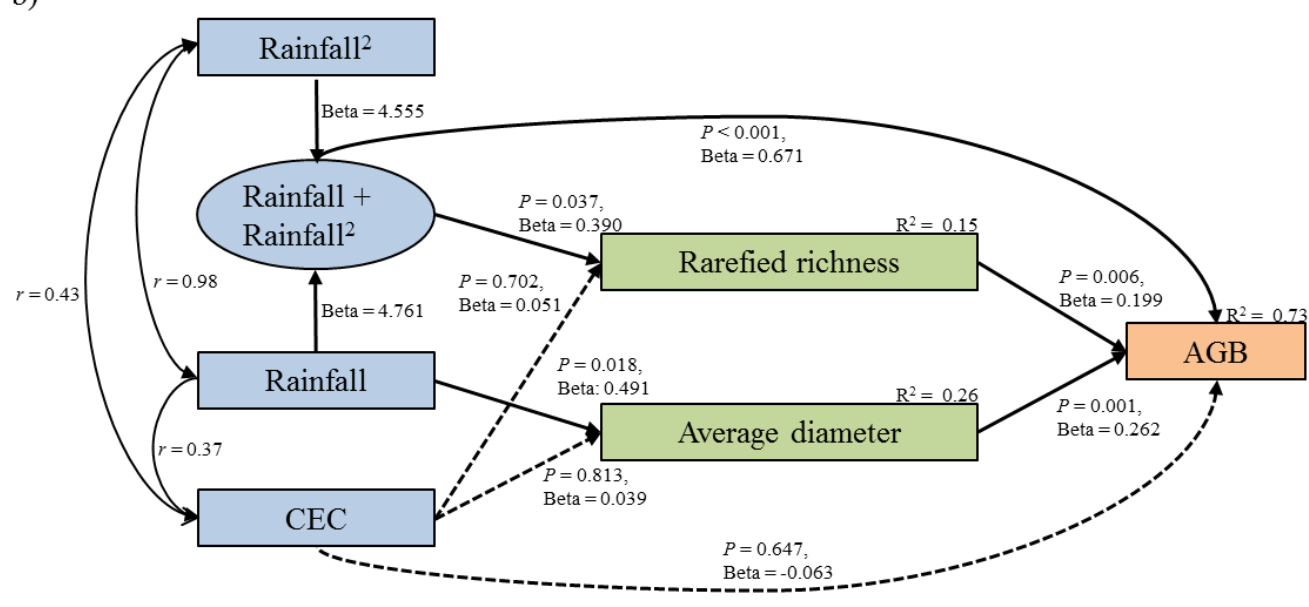


713 Figure 2. Map of vegetation cover in Latin America, with the location of the 60 study sites. a) above714 ground biomass (AGB, Mg/ha), b) Rarefied species richness (\# species/50 trees), and c) average tree 715 diameter $(\mathrm{cm})$. The size of the symbol scales with the value of the attribute. The intensity of the green 716 color indicates the amount of forest cover.The background layer is derived from a MODerate resolution 717 Imaging Spectroradiometer (MODIS) vegetation continuous fields (VCF) product (Hansen et al. 2003)

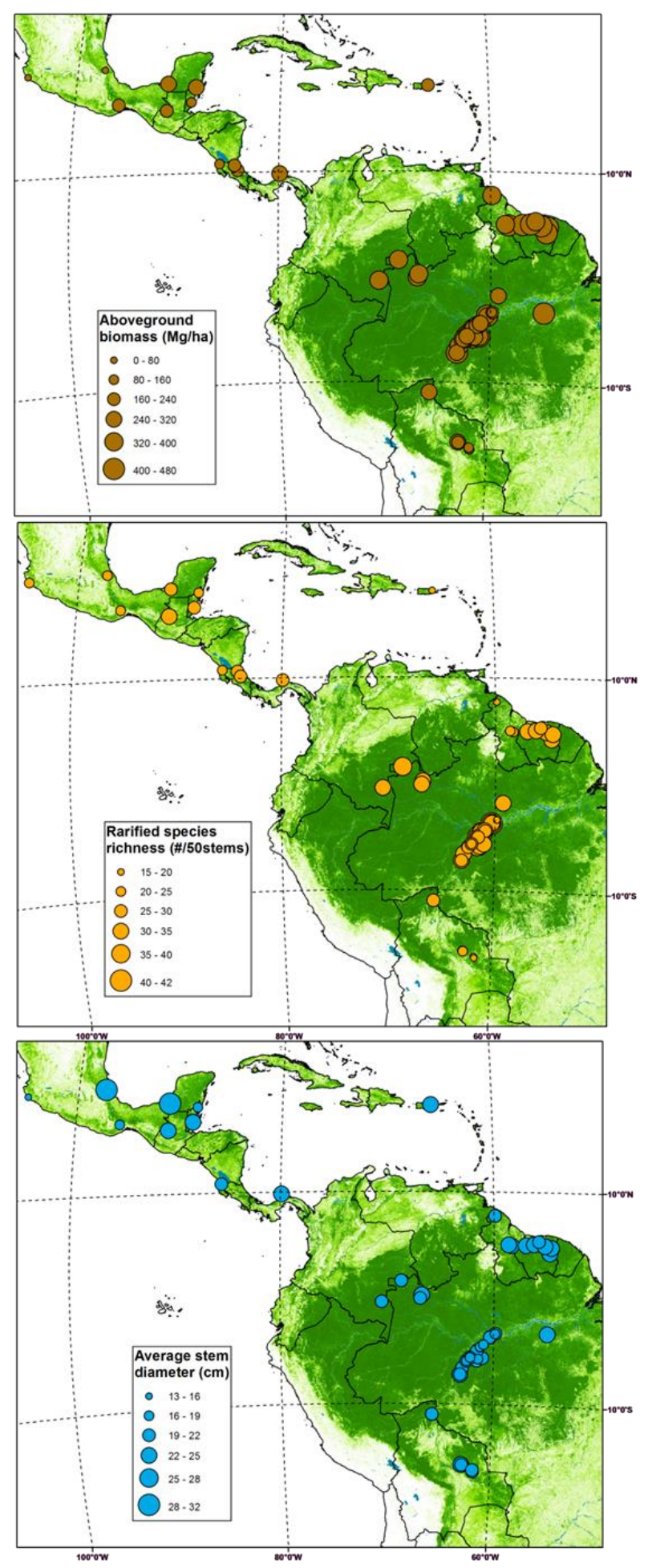


719 Figure 3. Relationship between above-ground biomass (AGB) and three taxonomic attributes; species

720 richness per unit area (top panels), Shannon diversity (middle panels), and rarefied species richness per 50

721 stems (bottom panels). Relationships are shown for 0.1 ha plots (left panels, $\mathrm{N}=47-53$ sites and 916-1837

722 plots) and 1 ha plots (right panels $\mathrm{N}=25$ sites and 294 plots). All data are based on trees $\geq 10 \mathrm{~cm}$ dbh. Dots

723 indicate the observed values. Regression lines are shown for each site (for the 1-ha plots), or several

724 regression lines are shown per site ( 0.1 ha plots within a 1 ha plot). Continuous regression lines are

725 significant, broken regression lines are not significant $(\mathrm{P}>0.05)$.
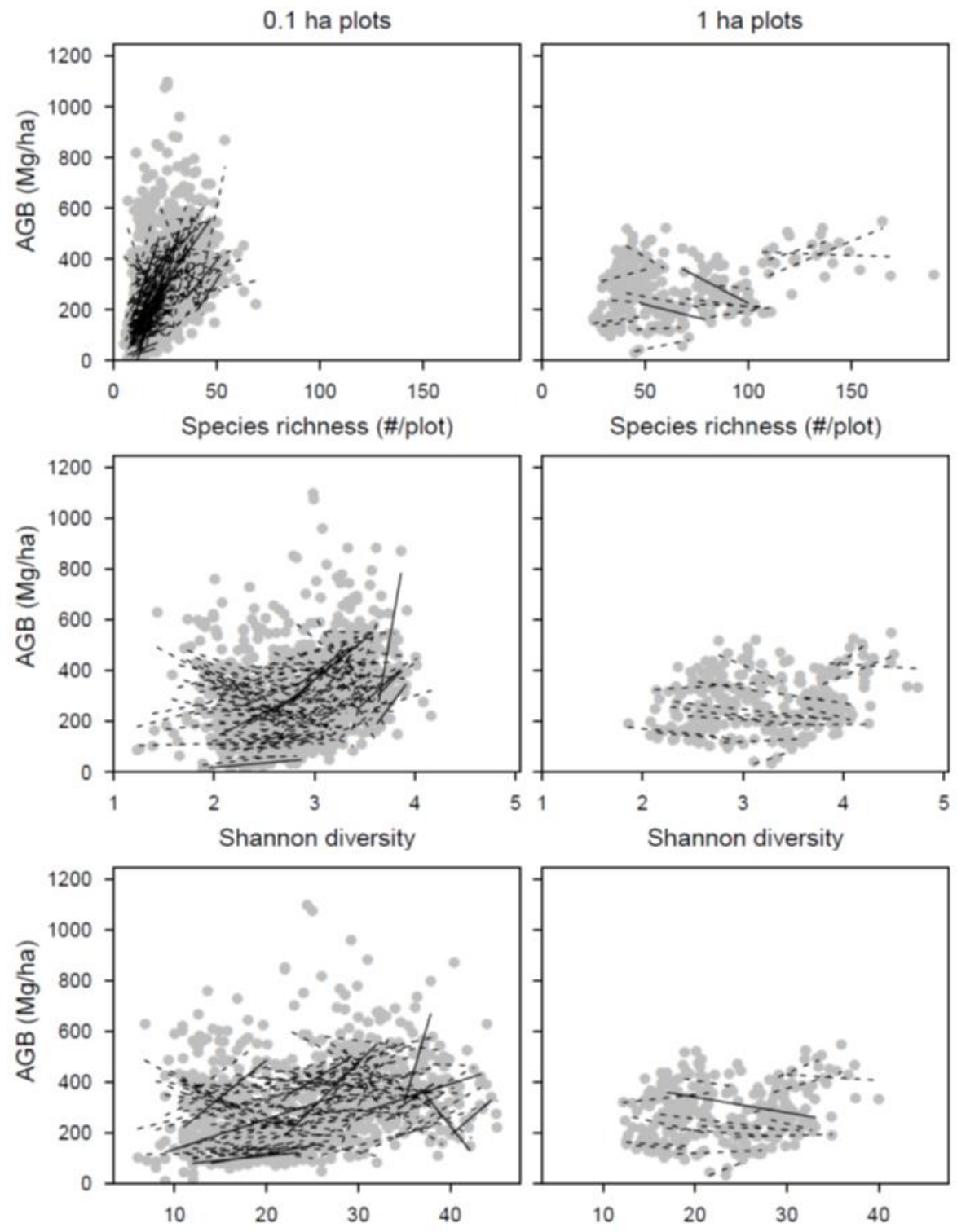

Rarefied richness (\#/50 stems)

Rarefied richness (\#/50 stems) 
727 Figure 4. Relationship between above ground biomass (AGB) and four structural attributes; tree density 728 (top panels), average tree diameter (upper middle panels), stand basal area (lower middle panels), and 729 density of large trees ( $\geq 60 \mathrm{~cm} \mathrm{dbh}$ ) (bottom panels). Relationships are shown for 0.1 ha plots (left panels, $730 \mathrm{~N}=53$ sites and 1837 plots) and 1 ha plots (right panels $\mathrm{N}=25$ sites and 294 plots). All data are based on 731 trees $\geq 10 \mathrm{~cm}$ dbh, with the exception of the density of large trees. Dots indicate the observed values.

732 Regression lines are shown for each site (for the 1-ha plots), or several regression lines are shown per site 733 (0.1 ha plots within a 1 ha plot). Continuous regression lines are significant, broken regression lines are 734 not significant $(\mathrm{P}>0.05)$.
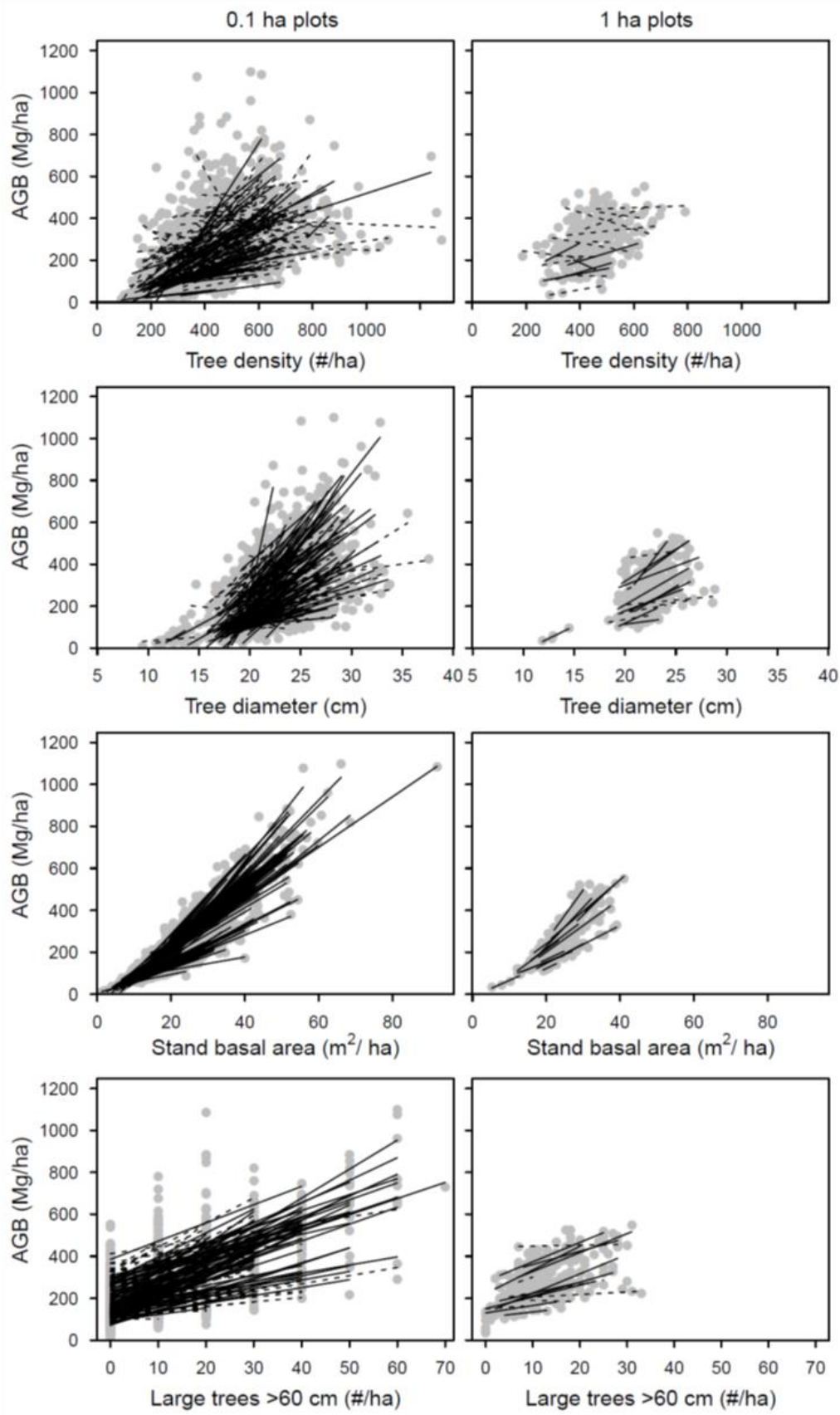
736 Figure 5. Meta-analysis of the within-site correlation between above-ground biomass (AGB) and

737 taxonomic attributes and structural attributes. Correlations are shown at two spatial scales; 0.1 ha plots

738 (black bars) and 1 ha plots (grey bars). Taxonomic attributes (shown below the dashed line) are rarefied

739 species richness at 50 stems (Rarefied Rich50), Shannon diversity (Shannon), species richness (Richness).

740 Structural attributes (shown above the dashed line) are tree density, average tree diameter, density of large

741 trees $\geq 60 \mathrm{~cm}$ dbh, and stand basal area. Means and 95 percent confidence intervals are shown. $\mathrm{N}=103$ -

742196 correlations for 0.1 ha plots, and $\mathrm{N}=16-17$ correlations for 1 ha plots.

743

744

745

746

747

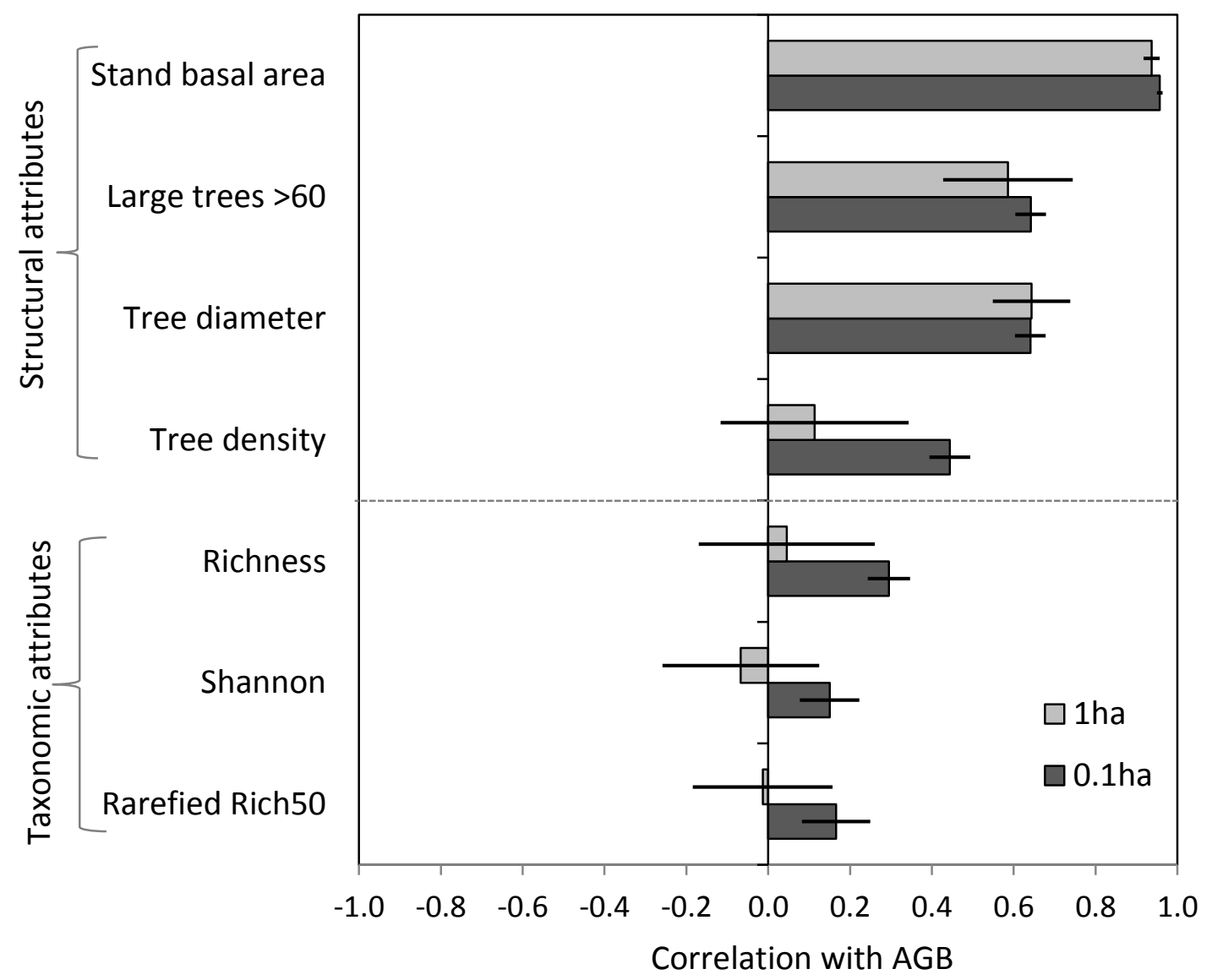


748 Figure 6. Relationship between annual rainfall and a) rarefied species richness; b) average tree diameter, 749 and c) above-ground biomass (AGBs) for 58 Neotropical forest sites. For each site, average values were 750 calculated for the largest plot size available ( 1 ha plots or 0.1 ha plots). All data are based on trees $\geq 10 \mathrm{~cm}$ $751 \mathrm{dbh}$. Regression lines and coefficients of determination $\left(\mathrm{R}^{2}\right)$ are shown. *** $\mathrm{P}<0.001 ; * * \mathrm{P}<0.01$.
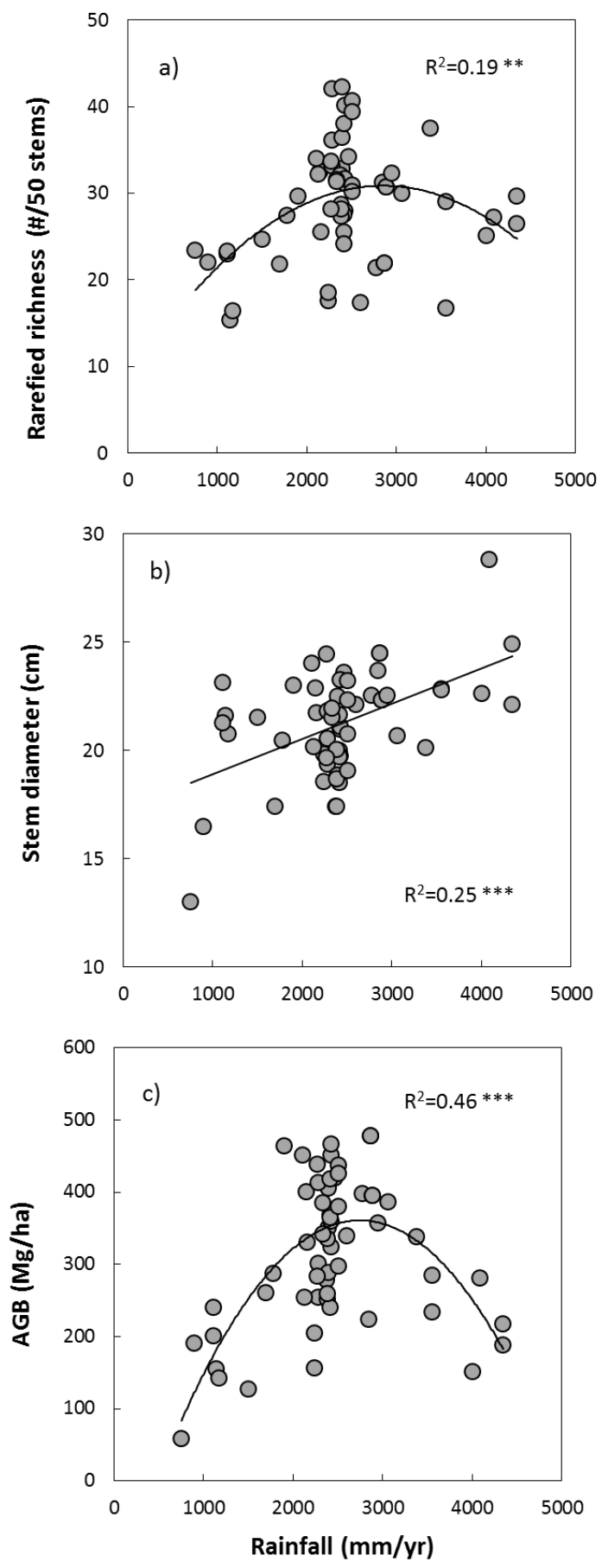
754 Figure 7. Relationship between above-ground biomass (AGB) and a) rarefied species richness; b), average 755 tree diameter for 58 Neotropical forest sites. For each site, average values were calculated for the largest 756 plot size available ( 1 ha plots or 0.1 ha plots). All data are based on trees $\geq 10 \mathrm{~cm} \mathrm{dbh}$. Regression lines 757 and coefficients of determination $\left(\mathrm{R}^{2}\right)$ are shown. *** $\mathrm{P}<0.001$.

758
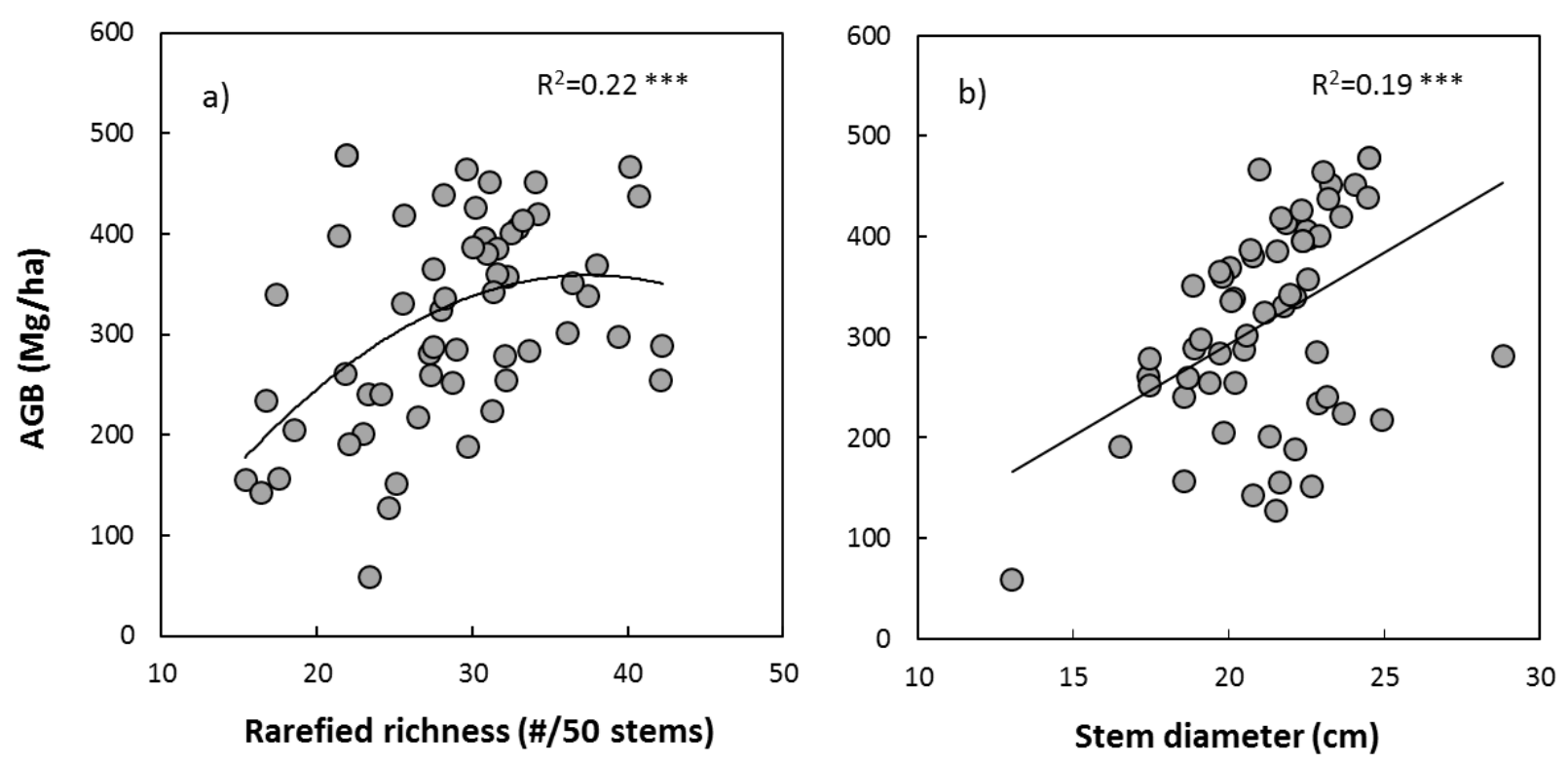

760

761 


\section{Supporting information}

763 Appendix S1. Overview of sites included in the study.

764 Appendix S2. Extended methods.

765 Appendix S3. Above-ground plot biomass estimates using the Chave and Brown equations and using 766 different diameter cutoff limits.

767 Appendix S4. Mixed linear model results of the relationship between above-ground biomass and 768 taxonomical and structural forest attributes at the 0.1 ha and 1 ha level.

769 Appendix S5. Strength of the relation between aboveground biomass, species richness and stem density 770 versus annual rainfall of the sites.

771 Appendix 6. Relationship between Cation Ecxhancge Capacity and rarefied richness, average stem

772 diameter and aboveground biomass.

773 Appendix S7. Standardized coefficients of the indirect paths in the structural equation model.

774 Appendix S8. Relationship between average above-ground biomass at a site and annual rainfall. 